\title{
Orally administered fisetin as an immuno-modulatory and therapeutic agent in a mouse model of chronic allergic airway disease
}

\author{
Pramathadhip Paul ${ }^{1}$, Sourav Majhi ${ }^{2}$, Shinjini Mitra ${ }^{1}$, Ena Ray Banerjee ${ }^{1, *}$
}

\begin{abstract}
${ }^{1}$ Immunology and Regenerative Medicine Research Laboratory, Department of Zoology, University of Calcutta, Kolkata, West Bengal, India

${ }^{2}$ Department of Zoology, Vidyasagar University, Midnapore, West Bengal, India
\end{abstract}

\section{Correspondence}

Ena Ray Banerjee, Immunology and Regenerative Medicine Research Laboratory, Department of Zoology, University of Calcutta, Kolkata, West Bengal, India

Email: enaraybanerjee@gmail.com

History

- Received: April 052019

- Accepted: June 152019

- Published: July 042019

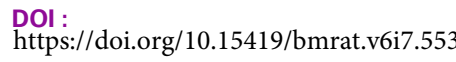

\section{Check for updates}

\section{Copyright}

(C) Biomedpress. This is an openaccess article distributed under the terms of the Creative Commons Attribution 4.0 International license.

The Open Access Publisher

\begin{abstract}
Introduction: Allergic asthma is a prevalent disorder, in which eosinophilic inflammation is involved in the lungs. Asthma affects people all over the world, regardless of the country's level of development. Chronic allergen-induced fibrotic damage of the lungs is stimulated in 55 days, which results in significant tissue destruction constitutive to pulmonary tissues, in addition to extensive oxidative \& inflammation-induced damage of small and large airways. To date, there is no cure for asthma, and symptoms are controlled using corticosteroids, which may cause systemic side effects. Flavonoids, like fisetin, are a class of secondary metabolites produced by plants, which are known to have numerous beneficial effects. Previous report demonstrated that fisetin has beneficial effects against various diseases such as cancers, tumors, diabetes, and alcohol-induced liver injury. Methods: In the present study, chronic allergic disease (asthma) was developed in C57BL/6J mice, using intraperitoneal injection of ovalbumin for 54 days together with orally administered fisetin as a treatment strategy. Fisetin was administered 1 hour before intratracheal treatment. On day 55, treated animals were sacrificed, and tissues were collected for various assays. Results: Fisetin was found to reduce the symptoms of asthma significantly. Reduction in total cell infiltration, eosinophil count, and the levels of serum IgE were observed. There was a down regulation in $\mathrm{CD}^{+}{ }^{+} \mathrm{CD} 4^{+} \mathrm{T}_{H}$ cells, and a decrease in the deposition of collagen in the lung and airways. Conclusion: From these observations, we conclude that fisetin is effective in the treatment of asthma, and a pathway by which fisetin acts was hypothesized.
\end{abstract}

Key words: Asthma, chronic allergy, fisetin, ovalbumin, airway hyper-responsiveness, TH2 response, NF $\kappa$ B, JAK/STAT

\section{INTRODUCTION}

Asthma is a common chronic respiratory disease, which involve inflammation of the airways or the bronchial tubes of the lungs ${ }^{1}$. It is a major noncommunicable disease that affects over 200 million people all over the world ${ }^{2}$. Asthma can be fatal if not treated properly (WHO, 2017) ${ }^{2}$. The prevalence of asthma can be traced back to ancient Egypt, when it was treated by drinking a mixture, called kyphi, made of several herbs and berries ${ }^{3}$. Chronic allergic asthma involves inflammation of the airways, causing them to swell, and causes the muscles to become tight, obstructing the flow of air in the airways ${ }^{1}$. Such obstruction along with bronchospasm and airway hyperresponsiveness (AHR) leads to asthma-related symptoms, such as bronchoconstriction, coughing, wheezing, tightness of chest and breathing shortness ${ }^{1,4,5}$. Although the major cause of asthma is unknown, a combination of environmental and genetic factors was shown to be involved in allergic diseases ${ }^{6}$. Pre- clinical studies have shown that there is an increase in the level of inflammatory cells such as eosinophils, mast cells, and type $2 \mathrm{~T}$ helper cells $\left(\mathrm{T}_{H} 2\right)$ in allergic asthma ${ }^{4,5}$. Cytokine levels, mainly interleukins IL-4, IL-5, and IL-13, which are secreted by CD4 ${ }^{+}$ $\mathrm{T}_{H} 2$ cells, are also affected ${ }^{4,5,7}$. The transcription factor GATA3 plays an essential role in the expression of $\mathrm{T}_{H} 2$ cytokines $^{7}$. IL-4 is involved in the generation of $\operatorname{IgE}^{5,8}$, IL-5 promotes airway eosinophilia ${ }^{5,9}$ and IL-9 helps the induction, proliferation and differentiation of mast cells ${ }^{5}$. IL-13 is involved in the hypersecretion of mucus ${ }^{5}$ and the activation of inducible nitric oxide synthase (iNOS), thus leading to the production of nitric oxide ${ }^{7}$. Fibrosis of the airways is associated with asthma, in which eosinophilic infiltration and deposition of collagen lead to thickening of the epithelial basement membrane ${ }^{5}$. In this process, profibrotic cytokines, such as TGF $\beta$, are involved ${ }^{5}$.

Flavonoids are a class of secondary metabolites with polyphenolic structures, produced by plants and 
fungi ${ }^{10}$. Flavonoids are produced by plants for growth and protection of vegetables ${ }^{10}$. Their beneficial effects are documented, and are attributed to their anti-inflammatory, antioxidative and anticarcinogenic properties, and the ability to regulate enzymes, such as xanthine oxidase (XO) and cyclooxygenase $(\mathrm{COX})^{10}$. The structure of flavonoids is comprised of a 15-carbon skeleton, including two phenyl rings ( $A$ and $B$ ) and one heterocyclic ring (ring C) ${ }^{6}$ as shown in Figure 1.

According to the composition of the rings, flavonoids can be classified into flavones (e.g., luteolin), flavonols (e.g. fisetin), flavanones (e.g. hesperetin), isoflavones (e.g. daidzein), anthocyanidins (e.g. cyanidin) and flavanols (e.g. catechins) ${ }^{6}$.

Fisetin (3, 7, 3', 4'-tetrahydroxyflavone) is a flavonol with 4 hydroxyl groups at positions 3, 7, 3' and 4' of the flavonoid structure ${ }^{11}$ as shown in Figure 1. It is commonly found in such as like apples, strawberries and grapes, and vegetables like tomatoes, cucumbers, and onions ${ }^{12,13}$. Strawberries have the highest content of fisetin as compared to other fruits and vegetables $^{14}$. Fisetin bears the potential to be an effective antioxidant, anticarcinogenic, anti-inflammatory and immuno-suppressing agent ${ }^{12,13}$. It has been found that fisetin can suppress the secretion of $\mathrm{T}_{H} 2 \mathrm{cy}$ tokines (IL4, IL5, and IL13) from basophils, and prevent the activation of macrophages ${ }^{13}$. Fisetin can affect mast cells and inhibit their ability to release histamines and cytokines ${ }^{13}$. It can also inhibit the action of $\mathrm{I} \kappa \mathrm{B}-\alpha$ kinase (IKK) in cancer cells, thereby inhibiting the activation of $\mathrm{NF} \kappa \mathrm{B}^{13}$.

\section{MATERIALS AND METHODS}

\section{Ethical approval}

Experiments were performed as per rules given by the departmental and institutional animal ethics committee. All animals were reared in the animal house (free of any pathogen) of the Department of Zoology under University of Calcutta.

\section{Mice}

Male C57BL/6J mice (8-10 weeks) of body weight 2025 grams were classified into three groups $(n=5$ for each group):

$$
\begin{aligned}
& \text { - Control } \\
& \text { - Ova } \\
& \text { - Ova+F }
\end{aligned}
$$

Ovalbumin-induced asthma \& fisetin treatment

The mice from Ova group were sensitized with the help of $100 \mu \mathrm{g}$ of Ovalbumin (Ova) grade-V (SigmaAldrich), forming complex with $\mathrm{Al}(\mathrm{OH})_{3}$ in a $0.2 \mathrm{ml}$ volume, and administered intraperitoneally on day $0^{15-17}$. They were challenged with $250 \mu \mathrm{g}$ intratracheal Ova on day 8 (intratracheally), and with 125 $\mu \mathrm{g}$ Ova on $15^{\text {th }}, 18^{\text {th }}, 21^{\text {st }}, 24^{\text {th }}, 27^{\text {th }}, 30^{\text {th }}, 33^{\text {rd }}$, $36^{\text {th }}, 39^{\text {th }}, 42^{\text {nd }}, 45^{\text {th }}, 48^{\text {th }}, 51^{\text {st }}$ and $54^{\text {th }}$ day respectively ${ }^{16}$. For intratracheal treatment, the mice were anesthetized for a short period by isoflurane inside a standard anesthesia chamber. Anesthetized mice were taken from the chamber, positioned in a supine posture, and tongue was extended with lined forceps. After this, they were sensitized with $50 \mu \mathrm{L}$ of Ova (at concentrations as mentioned above) placed at the back of its tongue ${ }^{16}$. Mice of the control group received normal saline.

Mice of Ova + F group were treated with oral $2 \mu \mathrm{M} / \mathrm{Kg}$ fisetin $(50 \mathrm{nM})$ dissolved in DMSO one hour before each intratracheal challenge. (Source of Fisetin: Cellular Neurobiology Laboratory, Salk Institute for Biological Studies, USA). A diagram of the treatment regime is presented in Figure 2.

\section{Airway hyperresponsiveness (AHR) mea- surement}

By using whole body plethysmography in unrestrained mice, airway hyper-responsiveness (AHR) was measured on day 55 i.e. 24 hours after the last intratracheal treatment. Before recording the data, the chambers of the 2 mice whole body plethysmograph (emka Technologies, France) were calibrated with 5 $\mathrm{ml}$ air. Mice of each group were placed in the chambers, acclimatized for 10 minutes and exposed to increasing concentrations $(0,5,10,15,20 \mathrm{mg} / \mathrm{ml})$ of methacholine (TCI, Japan) in PBS for 1 minute. Enhanced pause (Penh) was recorded for 4 minutes after each challenge.

\section{Sacrifice and collection of tissues}

Mice were sacrificed on the $55^{\text {th }}$ day by cervical dislocation after taking measurement of whole-body plethysmography, and the following tissues were collected.

\section{Peripheral blood (PB)}

After performing cardiac puncture, $1 \mathrm{ml}$ of blood was collected in tubes that contain EDTA $(1.5 \mathrm{mg} / \mathrm{ml})$ as an anticoagulant. To view under microscope, a blood smear was prepared on a microscopic slide. 


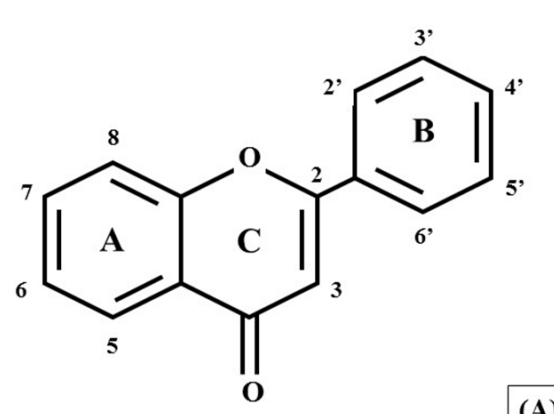

(A)

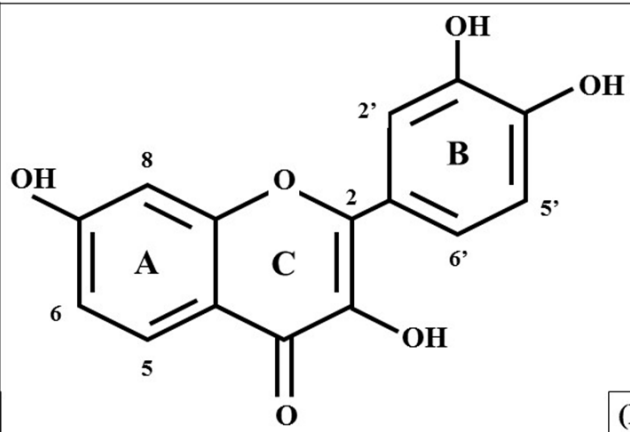

(B)

Figure 1: (A) Representative structure of flavonoids, with 2 phenyl rings (Rings A \& B) and 1 heterocyclicring (Ring C). (B) Structure of Fisetin, with hydroxyl groups on C3, C7, C4' and C5'.

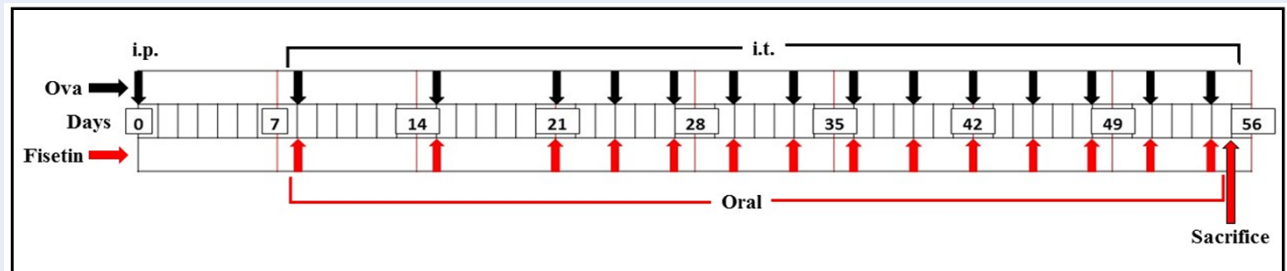

Figure 2: Treatment regime for the establishment and treatment of asthma in mice. Ovalbumin was administered intraperitoneally on day 0 and intratracheally on days $8,15,21,24,27,30,33,36,39,42,45,48,51$ and 54 . $50 \mathrm{nM}$ fisetin was administered orally 1 hour before Ova from day 8. Mice were sacrificed on day 55 .

\section{Bronchoalveolar lavage fluid (BALF)}

Both lungs were injected with $1 \mathrm{ml}$ of cold PBS slowly and then by drawing it out, BALF was collected ${ }^{18}$. The BALF was centrifuged at $200 \mathrm{X} g$ at $4^{\circ} \mathrm{C}$ for $10 \mathrm{~min}$. The cell pellet was resuspended in fetal bovine serum and a smear was made on a microscope slide.

\section{Lung parenchyma}

Immediately after collecting the BALF, the lungs were washed with PBS.

\section{Assays}

One lung was taken in a Petri dish and minced into digestible pieces. These pieces of lung were then digested using a $1 \mathrm{X}$ collagenase/ hyaluronidase cocktail (Stem Cell Technology) overnight at $37^{\circ} \mathrm{C}$. To get a single cell suspension, it was filtered through a no. 60 sieve (Sigma-Aldrich).

\section{Hydroxyproline estimation}

Whole lung tissue was washed, minced and finally vacuum dried to remove oxygen and the hydroxyproline was estimated to measure the overall collagen content of the lung.

\section{For gene \& protein expression}

For gene expression studies, whole lung was stored in RNA later solution (Ambion, Inc.) at $-80^{\circ} \mathrm{C}$. For protein expression studies, whole lung was washed with PBS and stored at $-80^{\circ} \mathrm{C}$.

\section{For histology}

One lung was collected in whole in $10 \%$ buffered formalin.

\section{Total cell (TC) count}

To determine cell viability, PB/ BALF was mixed with Trypan Blue dye (HIMEDIA, India) in 1:1 ratio. Further, it is observed under a microscope by using hemocytometer.

\section{Differential cell (DC) count}

Thin smear of cells was put on a slide. The PB/ BALF smears were immediately air-dried followed by methanol fixation (SRL, India). Staining was carried out using Wright- Giemsa (SRL, India) for $15 \mathrm{~min}$, then washed under running distilled water, and observed under a light microscope (Dewinter Fluorex 
LED) at $40 \mathrm{X}$ magnification ${ }^{19}$. Their nuclear morphology characterized different cell types.

\section{Ova-specific serum IgE}

Mouse purified IgE was purchased from BD Biosciences, USA and the provided protocol were followed (BD OptEIA Mouse IgE ELISA Set). 96-well microtitre plates were coated with (Corning, USA) 50 $\mathrm{mg} / \mathrm{ml}$ ovalbumin in sterile PBS overnight at $4{ }^{\circ} \mathrm{C}$.

Plates were washed with PBS-Tween $(0.05 \%)$ three times. Blocking was done by $5 \%$ skimmed milk in PBS for 1 hour at room temperature. After washing, $50 \mu$ plasma samples (1:10 dilution in blocking buffer) were added per well and incubated for $90 \mathrm{~min}$ at $37^{\circ} \mathrm{C}$. Wells were then washed 4 times with washbuffer. Biotin-labeled $2 \mu \mathrm{g}$ rat anti-mouse IgE (clone R35-118; BD Biosciences, USA) was added to each well for 1 hour at $37{ }^{\circ} \mathrm{C} .100 \mu \mathrm{l}$ avidin- HRP (BD Biosciences, diluted 1: 1000 in blocking buffer) was added in each well, followed by incubation for $90 \mathrm{mins}$ at $37^{\circ} \mathrm{C}$. TMB substrate $(3,3,5,5$, tetramethylbenzidine; Sigma Aldrich) was added to each well at room temperature for $30 \mathrm{~min}$. Color development was measured at $405 \mathrm{~nm}$ by using ELISA plate reader (Thermo Scientific). Serum containing IgE was determined by using a standard curve prepared using purified IgE (BD Biosciences).

\section{CFU-c assay}

To assess progenitors from all lineages, colony forming unit-cell assay was performed. Methylcellulose was used to make semisolid media (HIMEDIA, India). Semisolid media composed with IMDM (HIMEDIA, India), 30\% FBS (HIMEDIA, India), 20 $\mathrm{mg} / \mathrm{ml}$ BSA (Biosera), 1\% Pen-Strep (HIMEDIA, India). Stem cell factor (Biovision) was added at the concentration of $5 \mathrm{ng} / \mathrm{ml}$. All constituents were mixed thoroughly by vortexing. $1.5 \%$ methylcellulose (HIMEDIA, India) was added into this mixture. Each 24 well plates (Nest Biotech) was filled with $1 \mathrm{ml}$ of semisolid media. Next, $10^{6}$ cells were added to each well based on treatment groups and control groups in triplicate and incubated at $37^{\circ} \mathrm{C}$ in a $5 \% \mathrm{CO}_{2}$ humidified chamber (Thermo Fisher) for 7 days. Colonies were counted after 7 days and the clonogenic potential of the sample was measured by dividing the number of colonies obtained by the total number of plated cells.

\section{Gene expression}

RNA was isolated from lung tissues with TRIzol reagent (Life Technologies, USA). cDNA was prepared using reverse transcriptase III. Total mRNA was assessed by Reverse Transcriptase PCR (RT-PCR) and Real time PCR (qRT) as previously described ${ }^{20}$.

\section{Real time ( $q R T)-P C R$}

Total mRNA were assessed by quantitative PCR (qPCR) analysis as previously mentioned ${ }^{20}$. The primers used for Real time PCR are listed in Table 1 A, with $\beta$-actin as the internal control.

\section{Reverse Transcriptase (RT)-PCR}

mRNA expression of different cytokine genes were assessed by RT-PCR as previously described ${ }^{20}$. Gene specific primers are listed in Table $1 \mathrm{~B}$ and GAPDH was taken as a house-keeping gene.

\section{Flow cytometry}

Flow cytometry was carried out employing BD FACSVerse (BD Biosciences, USA), and the results were analyzed using the FACSSuite (BD Biosciences, USA) software for analysis. Cell surface staining was performed using the conjugated antibodies: CD45-conjugated with PerCPCy5.5 (BioLegend), CD3e-conjugated with PE (BD Biosciences, USA), CD4- conjugated with V450 (BD Biosciences, USA), CD8a-conjugated with Alexa Fluor 488 (BD Biosciences, USA), B220-conjugated with FITC (BD Biosciences, USA), GR-1-conjugated with FITC (MACS), and F4/80-conjugated with PE (Invitrogen). Among the $\mathrm{CD} 45^{+}$hematopoietic cells are $\mathrm{T}$ cells $\left(\mathrm{CD} 45^{+} \mathrm{CD} 3\right)$ and $\mathrm{B}\left(\mathrm{CD} 45^{+} \mathrm{B} 220\right)$ cells. Of the $\mathrm{CD}^{+}$cells, $\mathrm{CD}^{+}{ }^{+} \mathrm{CD} 4^{+}$are helper $\mathrm{T}\left(\mathrm{T}_{H}\right)$ cells, and $\mathrm{CD}^{+}{ }^{+} \mathrm{CD}^{+}$are cytotoxic $\mathrm{T}\left(\mathrm{T}_{C}\right)$ cells. Neutrophils are $\mathrm{CD} 45^{+} \mathrm{Gr} 1^{+}$, monocytes are $\mathrm{CD} 45^{+} \mathrm{F} 4 / 80^{\text {low }+}$ and macrophages are $\mathrm{CD} 45^{+} \mathrm{F} 4 / 80^{h i g h+16}$.

\section{Analysis of protein expression by Western blot}

Total cellular protein was isolated from lung tissues and primary antibodies were used to analyze the expression of proteins in allergen-sensitized mice. The antibodies were rabbit anti-mouse NF $\kappa \mathrm{B}$ (Santa Cruz), rabbit anti-mouse $\mathrm{TGF} \beta$, rabbit anti-mouse STAT6 (Santa Cruz) and rabbit anti-mouse GAPDH (Santa Cruz). Western blot protocol was described previously $^{20}$.

\section{Histology}

Right lobes from the lungs were separated and fixed immediately in $10 \%$ neutral buffer formalin. Lung samples were processed, dehydrated, embedded in paraffin, and sectioned to $5 \mathrm{~mm}$ thickness. Cellular infiltration and influx of inflammatory cells were visualized using standard histological techniques of hematoxylin and eosin staining as previously described 
Table 1: List of primers used for determination of gene expression by real time PCR (A) and reverse

transcriptase PCR (B)

\begin{tabular}{|c|c|c|c|c|c|}
\hline & Method & Gene & Type & Primer s & $\left(5^{\prime}-3^{\prime}\right)$ \\
\hline \multirow[t]{8}{*}{ A. } & qRT- PCR & $\beta$-actin & House-keeping gene & Forward & GTGGGCCGCTCTAGGCACCAA \\
\hline & primers & & & Reverse & CTCTTTGATGTCACGCACGATTTC \\
\hline & & IL3 & Cytokine genes & Forward & CCGTTTAACCAGAACGTTGAA \\
\hline & & & & Reverse & CCACGAATTTGGACAGGTTT \\
\hline & & IL4 & & Forward & GGCATTTTGAACGAGGTCAC \\
\hline & & & & Reverse & AAATATGCGAAGCACCTTGG \\
\hline & & IL5 & & Forward & \\
\hline & & & & Reverse & AGCCCCTGAAAGATTTCTCC \\
\hline \multirow[t]{14}{*}{ B. } & RT- PCR & GAPDH & House-keeping & Forward & TGTGATGGGTGTGAACCACGA \\
\hline & & & & Reverse & TGCTGTTGAAGTCGCAGGAGAC \\
\hline & & IL4 & Cytokine genes & Forward & TCGGCATTTTGAACGAGGTC \\
\hline & & & & Reverse & GAAAAGCCCGAAAGAGTCTC \\
\hline & & IL5 & & Forward & TCACCGAGCTCTGTTGACAA \\
\hline & & & & Reverse & ССАСАСТTCTСТTTTTGGCG \\
\hline & & IL13 & & Forward & GGTCCCTGGCAATATTACTGTAT \\
\hline & & & & Reverse & СССАТТСАСТАСАСАТСАССТТ \\
\hline & & IFN $\gamma$ & & Forward & ССTCTGAGACAATGAACGCT \\
\hline & & & & Reverse & AAAGAGATAATCTGGCTCTGC \\
\hline & & TGF $\beta$ & & Forward & ACCGCAACAACGCCATCTAT \\
\hline & & & & Reverse & GTAACGCCAGGAATTGTTGC \\
\hline & & iNOS & & Forward & СССTTCCGAAGTTTCTGGCAGCAGC \\
\hline & & & & Reverse & GGCTGTCAGAGCCTCGTGGCTTTGG \\
\hline
\end{tabular}

(Paul et al. 2018). Collagen deposition and pulmonary fibrosis in the lungs were also identified by Masson's trichrome staining ${ }^{9}$.

\section{Statistical analysis}

Data from the present study were analyzed using Graph Pad Prism 6. All values are represented as Mean \pm SEM, with $\mathrm{p}<0.05$. Statistical significance has been calculated by t-test. ${ }^{*}$ has been used to denote significance with respect to control samples, and \# has been used to denote significance in comparison to Ova- treated samples.

\section{RESULTS}

In this study, we have established ovalbumin-induced chronic allergic asthma in C57BL/J mice, and $2 \mu \mathrm{M} / \mathrm{kg}$ fisetin $(50 \mathrm{nM})$ was administered orally one hour before each intratracheal challenge.

Induction of asthma was confirmed by the increase in the Penh value following exposure to methacholine (data not shown), and the infiltration of cells into the blood (by 5.15 folds; $\mathrm{p}<0.05$; Figure $3 \mathrm{~A}$ ). Infiltration of cells was 6.01 folds higher in BALF compared to untreated control $(p<0.05$; Figure $3 \mathbf{B})$ and in the lung, the value was 2.51 folds higher $(\mathrm{p}<0.05$; Figure $3 \mathrm{C}$, E).

Influx of eosinophils in the blood increased 3.50 folds ( $p<0.05$; Figure $4 \mathrm{~A}$ ), and the BALF has 2.50 folds more than control group. ( $p<0.05$; Figure $4 B$ ). In peripheral blood, there was a 5.12 folds more $\mathrm{CD} 45^{+} \mathrm{B} 220^{+} \mathrm{B}$ cell population (Figure $5 \mathrm{~B}, \mathrm{~J}$ ), a 7.65 folds more $\mathrm{CD}_{4} 5^{+} \mathrm{CD}^{+} \mathrm{T}$ cell population $(\mathrm{p}<0.05)$ (Figure 5E, J), a 7.19 folds more $\mathrm{CD}^{+} \mathrm{CD}^{+} \mathrm{T}_{H}$ cell population $(\mathrm{p}<0.05)$ (Figure $5 \mathrm{E}, \mathrm{J})$ ) a 9.48 

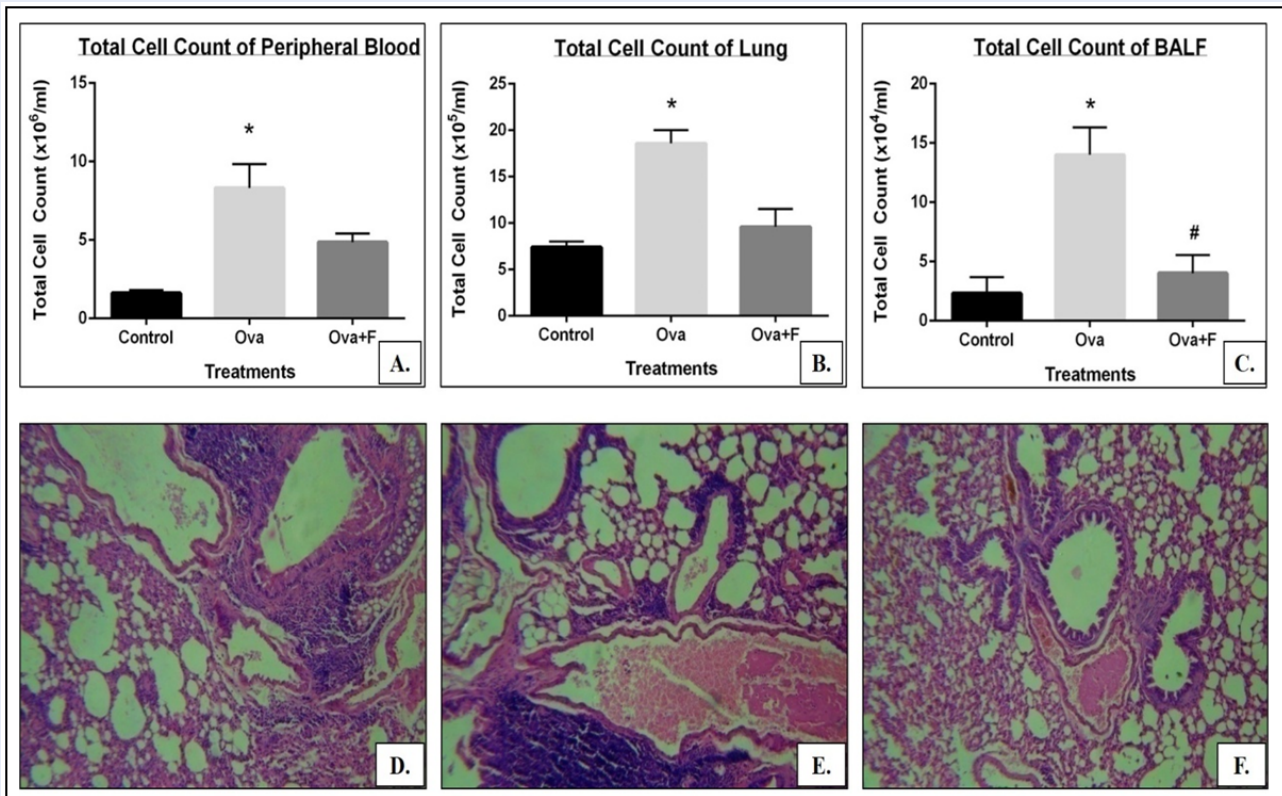

Figure 3: Infiltration of cells in the blood, BALF and lung were inhibited by Fisetin. The TC of blood 5.15 fold more with Ova, and down regulated by 1.71 fold with fisetin (A). The TC of lung upregulated significantly, by 2.51 fold with Ova, and down regulated by 1.94 fold with fisetin (B). The TC of BALF also up regulated significantly, by 6.01 fold with Ova, and down regulated by 3.47 fold with fisetin (C). Lung sections were stained with hematoxylineosin staining showed more migration of infiltration cells in the lung with Ova (E), compared to control (D). Infiltration of cells were inhibited by fisetin (F). ${ }^{*} p<0.05$, compared to control; \# $p<0.05$, compared to Ova).

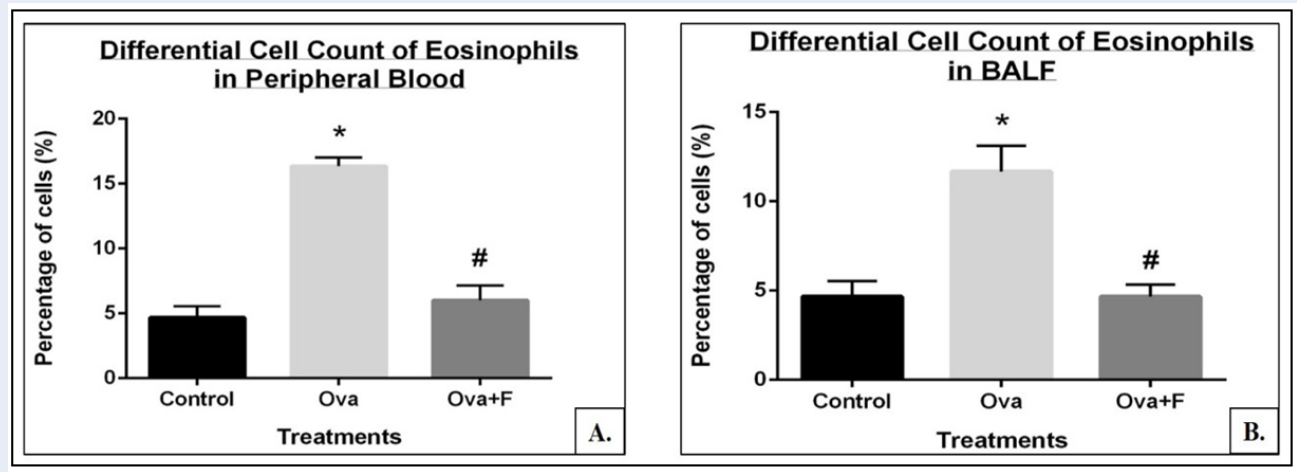

Figure 4: Eosinophilic infiltration in the blood and BALF were inhibited by fisetin. The number of eosinophils in the blood was found to be 3.50 fold more with Ova, and reduced by 2.72 fold with fisetin (A). Eosinophils in the BALF was found significantly more by 2.50 fold with Ova, and reduced by 2.50 fold with fisetin $(\mathbf{B}) .\left({ }^{*} \mathrm{p}<0.05\right.$, compared to control; $\# p<0.05$, compared to Ova). 
folds more $\mathrm{CD}^{+}{ }^{+} \mathrm{CD} 8^{+} \mathrm{T}_{C}$ cell population $(\mathrm{p}<0.05)$ (Figure 5E, J), a 3.95 fold more $\mathrm{CD}_{4} 5^{+} \mathrm{GR} 1^{+}$neutrophil population $(\mathrm{p}<0.05)$ (Figure $5 \mathbf{H}, \mathbf{K})$, a 5.42 fold more $\mathrm{CD} 45^{+} \mathrm{F} 4 / 80^{\text {low }+}$ monocyte population $(\mathrm{p}<0.05)$ (Figure 5H, K) and a 8.98 fold more $\mathrm{CD} 45^{+} \mathrm{F} 4 / 80^{h i g h+}$ macrophage population $(\mathrm{p}<0.05)$ (Figure 5 H, K) compared to control group. In the lung, $\mathrm{CD} 45^{+} \mathrm{B} 220^{+} \mathrm{B}$ cell population displayed 3.34 fold increase (Figure 6B, J), while a 7.93 fold more $\mathrm{CD}_{4} 5^{+} \mathrm{CD}^{+} \mathrm{T}$ cell population (Figure 6E, J), a 24.33 fold more $\mathrm{CD}^{+} \mathrm{CD}^{+}{ }^{+} \mathrm{T}_{H}$ cell population (Figure 6E, J), a 29.70 fold more $\mathrm{CD}^{+}{ }^{+} \mathrm{CD}^{+}{ }^{+} \mathrm{T}_{C}$ cell population (Figure $6 \mathrm{E}, \mathrm{J}$ ), a 1.79 fold more $\mathrm{CD} 45^{+} \mathrm{GR} 1^{+}$neutrophil population (Figure 6H, K), a 3.52 fold more $\mathrm{CD} 45^{+} \mathrm{F} 4 / 80^{\text {low }}+$ monocyte (Figure $\mathbf{6 H}, \mathbf{K}$ ) and a 9.36 fold more $\mathrm{CD} 45^{+} \mathrm{F} 4 / 80^{\text {high }}+$ macrophage population (Figure 6 $\mathbf{H}, \mathbf{K})$ was observed compared to control group. Less than 0.05 of $\mathrm{P}$ value was considered statistically significant.

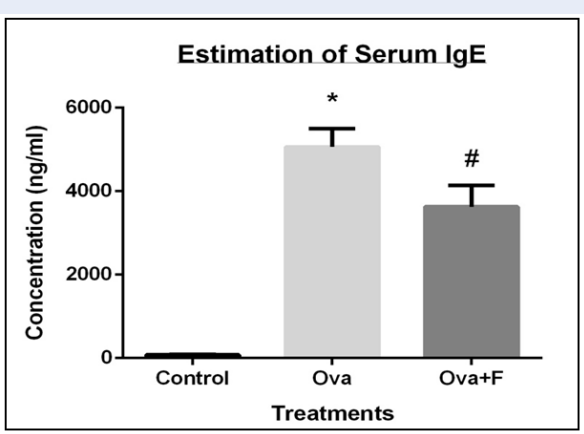

Figure 7: Concentration of Ova- specific IgE in serum was reduced by fisetin. Ova- specific IgE in the serum was observed to be 63.88 fold higher with Ova, and decreased by 1.40 fold with fisetin. ( ${ }^{*} \mathrm{p}<0.05$, compared to control; \# $\mathrm{p}<0.05$, compared to Ova). Denotes $p$ value $<0.05$ is considered statistically significant.

Serum IgE of the allergen-sensitized mouse was observed to be 63.88 folds higher (Figure 7) and a 3.16 folds higher collagen deposition in the lung (Figure 8 A, C). Expression of $\mathrm{T}_{H} 2$ genes like IL4 increased by 4.14 folds, IL5 increased by 1.56 folds and IL13 increased by 1.63 folds respectively. Expression of proinflammatory genes like IFN $\gamma$ increased by 1.33 folds, TGF $\beta$ increased by 1.88 folds, iNOS increased by 1.89 folds, NF $\kappa$ B, and STAT6. The clonogenic potential of the blood, BM, and lung cells decreased by 1.95 folds, 1.40 folds, and 1.20 folds, respectively.

Taken together, the data suggest that fisetin has a protective role in oval bumin-sensitized lung inflammation via its signal molecules. Fisetin inhibited the infiltration of cells into the blood by 1.71 folds (Figure 3A), into the BALF by 3.47 folds (Figure 3B) and into the lung by 1.94 folds (Figure 3C, F). Eosinophilic infiltration decreased by 2.72 folds in the blood (Figure $4 \mathrm{~A}$ ), and by 2.50 folds in the BALF (Figure 4B). In the blood, fisetin led to a 10.51-fold reduction in B cells (Figure $5 \mathrm{C}, \mathrm{J}$ ), a 4.22 -fold reduction in T cells (Figure 5F, J), a 5.54-fold decrease in the $\mathrm{T}_{H}$ cells (Figure 5F, J), a 4.34-fold decrease in the $\mathrm{T}_{C}$ cells (Figure 5F, J), a 2.27-fold decrease in monocytes (Figure 5I, K) and a 2.52-fold reduction in macrophages (Figure 5I, K). In the lung, fisetin led to a 2.94-fold reduction in B cells (Figure 6C, J), a 2.57fold reduction in the T cells (Figure 6F, J), a 1.45-fold reduction in the $\mathrm{T}_{H}$ cells (Figure $6 \mathrm{~F}, \mathrm{~J}$ ), a 5.60-fold reduction in the $\mathrm{T}_{C}$ cells (Figure $6 \mathrm{~F}, \mathrm{~J}$ ), a 6.28-fold reduction in monocytes (Figure 6I, K) and a 5.32-fold reduction in macrophages (Figure $6 \mathbf{I}, \mathbf{K}$ ).

Fisetin successfully reduced the serum IgE concentration by 1.40 folds (Figure 5), as well as the collagen deposition in the lungs by 2.05 folds (Figure $8 \mathrm{~A}$, D). Expression of the $\mathrm{T}_{H} 2$ genes IL4 was reduced by 4.27 folds, IL 5 reduced by 1.40 folds and IL13 reduced by 2.68 folds, as did the expression of TGF $\beta$ (by 1.07 folds), NF $\kappa$ B and STAT6 (Figure 9).

Fisetin, however, did not have a significant effect on the expression of IFN $\gamma$ and iNOS. Clonogenic potential of the blood, BM, and lung cells were restored by 3.17 folds, 1.32 folds, and 1.24 folds respectively with fisetin (Figure 6).

\section{DISCUSSION}

Bronchial inflammation and hyperresponsiveness in asthma are complex respiratory diseases. Over 15-20 million people are affected by asthma in India, and this number is rising with time ${ }^{2}$. To date, asthma cannot be completely cured, but it can be regulated using medications like corticosteroids ${ }^{2}$. Prolonged use of inhaled corticosteroids can lead to several systemic side effects such as osteoporosis, reduced bone density, glaucoma, cataracts, and bruising ${ }^{21}$. We designed a study to use fisetin, a natural compound, to treat chronic allergic asthma to overcome these limitations.

Fisetin is a natural product, which is readily available. Fisetin is a potent antioxidant and is thought to exert its antioxidant effect by activating heme oxygenaseI (HO-I) under oxidative stress conditions ${ }^{22}$. It has also been shown that fisetin suppresses $\mathrm{NF} \kappa \mathrm{B}$ signaling pathway and MAPKs. It inhibits the degranulation of basophils and mast cells and reduces the expression of IL4, IL13, and other cytokines by basophils and mast cells ${ }^{23}$. 


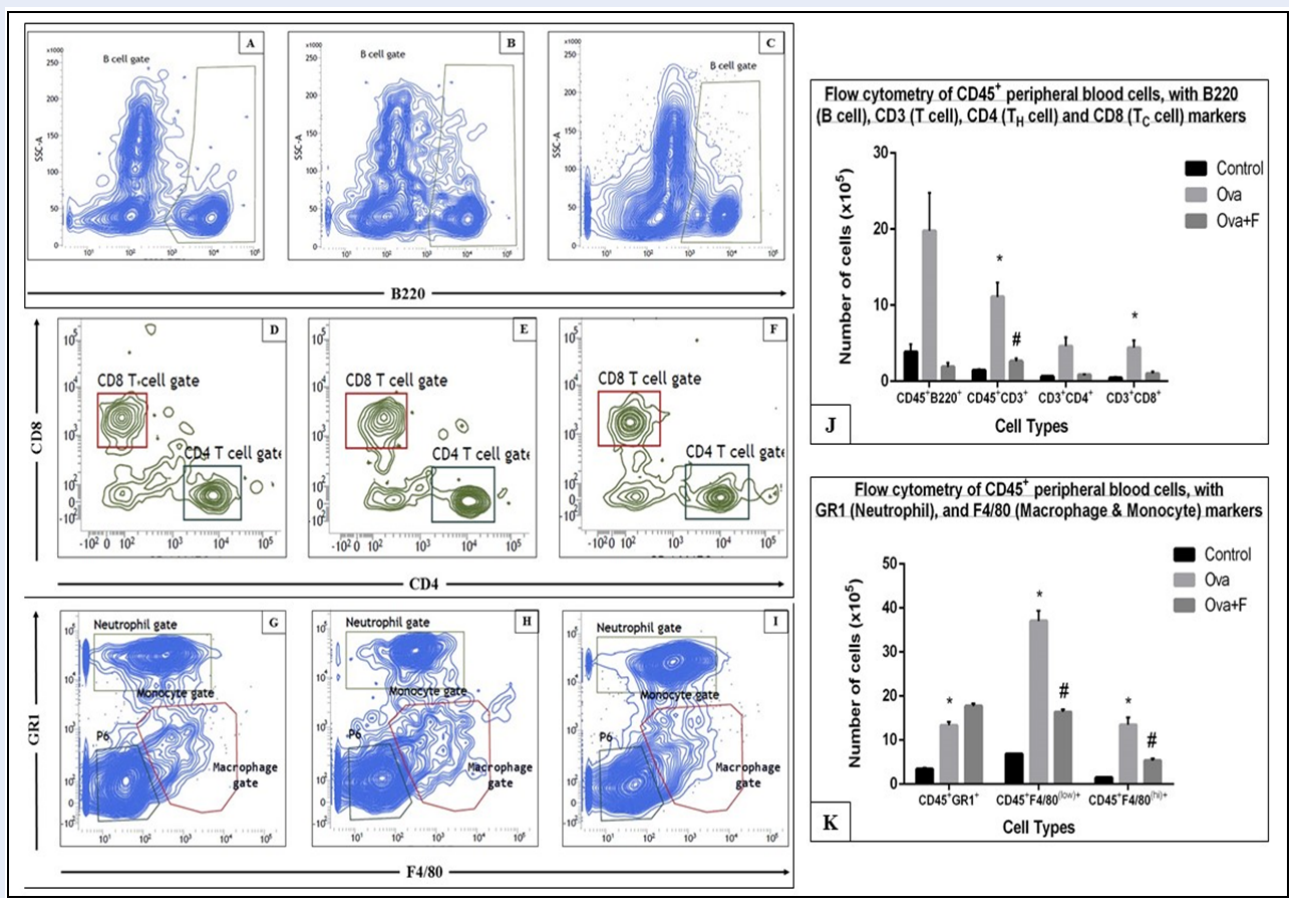

Figure 5: Fisetin inhibited the population of immune cells in the blood. Blood cells were pooled from 5 mice and stained with fluorescent tagged antibodies. $C D 45^{+} B 220^{+} B$ cells decreased by 5.12 fold $(\mathbf{A}, \mathbf{B}, \mathbf{C}, \mathbf{J})$, $\mathrm{CD}_{4}{ }^{+} \mathrm{CD} 3^{+} \mathrm{T}$ cells decreased significantly by 4.22 fold $(\mathbf{D}, \mathbf{E}, \mathbf{F}, \mathbf{J}), \mathrm{CD} 45^{+} \mathrm{CD} 3^{+} \mathrm{CD} 4{ }^{+} \mathrm{T}_{H}$ cells decreased by 5.54 fold (D, E, F, J), CD45 ${ }^{+} \mathrm{CD}^{+}{ }^{+} \mathrm{CD} 8^{+} \mathrm{T}_{C}$ cells decreased by 4.34 fold $(\mathbf{D}, \mathrm{E}, \mathrm{F}, \mathrm{J}), \mathrm{CD} 45^{+} \mathrm{F} 4 / 80^{\text {low }+}$ monocytes decreased significantly by 2.27 fold $(\mathbf{G}, \mathbf{H}, \mathbf{I}, \mathbf{K})$ and $C D 45^{+} \mathrm{F} 4 / 80^{\text {hight }}$ macrophages decreased significantly by 2.52 fold ( $G, H, I, K)$. ( ${ }^{*} p<0.05$, compared to control; \# $p<0.05$, compared to Ova). Less than 0.05 of P-value was considered statistically significant.

In vitro, studies with fisetin has been proved for its ability to inhibit the secretion of cytokines by basophils and mast cells ${ }^{13}$. Previously, it has been reported that $\mathrm{NF} \kappa \mathrm{B}$ activity in bronchial epithelial cells is inhibited by using fisetin. Our data also support that $\mathrm{I} \kappa \mathrm{B}-\alpha$ and nuclear translocation of $\mathrm{p} 65$ are blocked by fisetin. $\operatorname{IkB} \alpha$ is activated by the action of IKK and dissociates into $\mathrm{IkB}$, and later activates NFkB. NFkB translocates into the nucleus and further enables TLRs. Fisetin blocks IKK complex and finally inhibit NFkB activation ${ }^{24}$.

C57BL/6J mice showed robust Th2 responses when they were treated with ovalbumin challenge ${ }^{25,26}$. In ovalbumin-sensitized allergic asthma, IL4 production increases by the activation of mast cells ${ }^{17}$, followed by activation of B cells and finally synthesize $\operatorname{IgE}$ antibody.

When prolonged ovalbumin challenge was used, Tlymphocytes were activated, which further secreted Th2 cytokine IL-5 and regulated eosinophilic inflammation by proliferation and differentiation 27 . Eosinophils are thought to influx into the airway mucosa and AHR. Our preclinical data emphasize that total number of cells increased in ovalbumin challenges in BALF as well as blood, and eosinophils and lymphocytes in ova challenged mice were upregulated, where the value was downregulated in the treated group. Following chronic allergen challenge, treated mice group showed reduced AHR and Th2 cytokines (IL-4 and IL-5) in gene expression profile. Furthermore, a histological study revealed the breakdown of the alveolar wall, thickening of the smooth muscle layer, accumulation of infiltration of inflammatory cells deposited surrounding the inflamed region of the lung, and the accumulation of the mucin in the inner lumen of the bronchi, which result in a reduction of bronchiole lumen volume.

Similarly, the treated groups downregulated $\mathrm{CD} 4^{+}$ T-lymphocytes promotes a high level of Th2 cytokine including IL-5, IL-3 which support our data. Nuclear factor kappa B $(\mathrm{NF}-\kappa \mathrm{B})$ is the most important transcription factor which regulates multiple pro-inflammatory mediators and various interleukins. Activation of NF- $\kappa \mathrm{B}$ in epithelial cells upregulates the expression of TNF- $\alpha$. We found the lung 


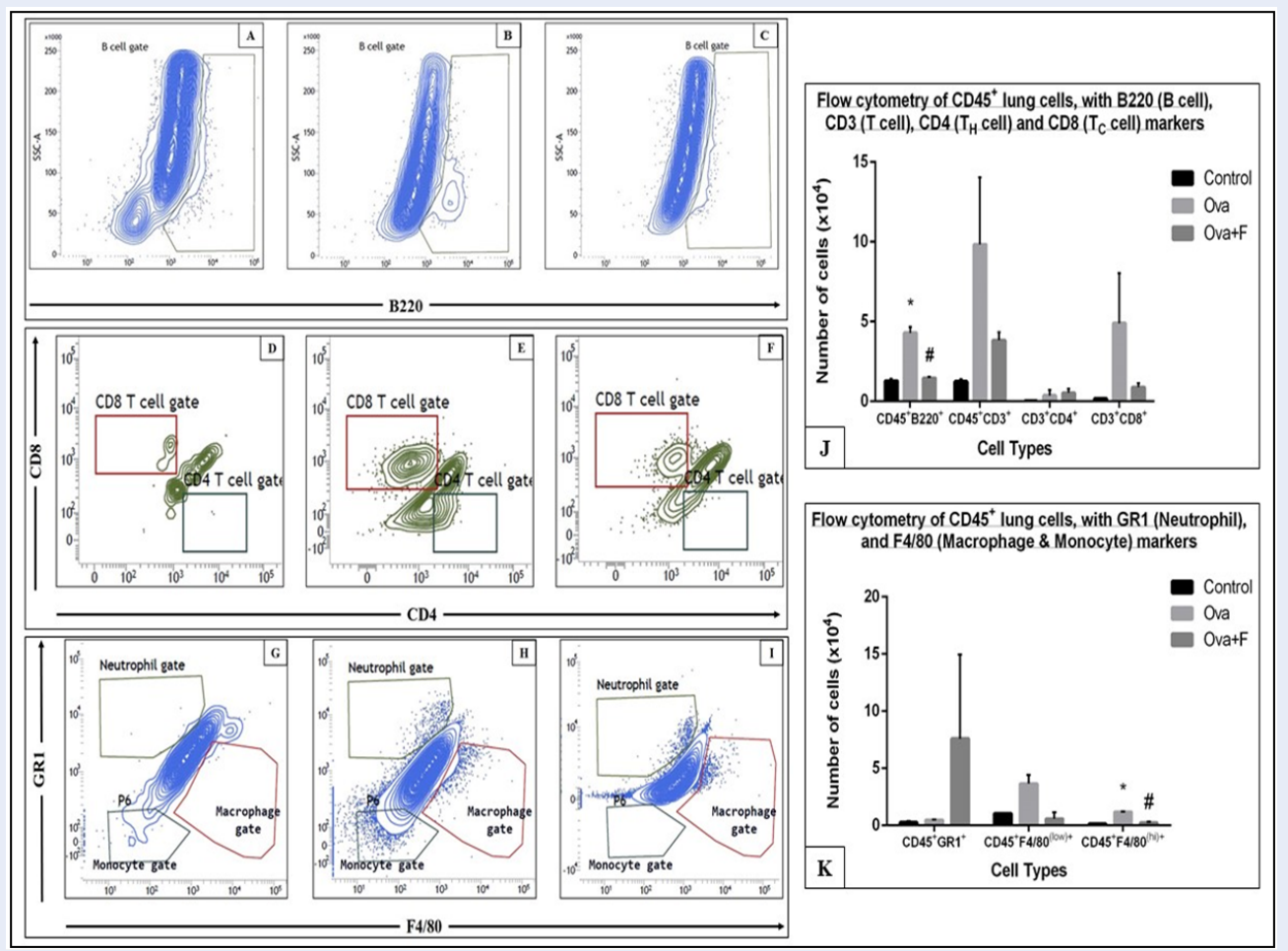

Figure 6: Fisetin inhibited the population of immune cells in the lung. Lung cells were pooled from $\mathbf{5}$ mice and stained with fluorescent tagged antibodies. $C D 45^{+} B 220^{+} B$ cells decreased significantly by 2.94 fold (A, B, C, J), $C D 45^{+} \mathrm{CD}^{+} \mathrm{T}$ cells decreased by 2.57 fold $(\mathbf{D}, \mathrm{E}, \mathrm{F}, \mathrm{J}), \mathrm{CD} 45^{+} \mathrm{CD} 3^{+} \mathrm{CD} 4^{+} \mathrm{T}_{H}$ cells decreased by 1.45 fold (D, E, F, J), $C D 45^{+} \mathrm{CD}^{+}{ }^{+} \mathrm{CD} 8^{+} \mathrm{T}_{C}$ cells decreased by 5.60 fold $(\mathbf{D}, \mathbf{E}, \mathbf{F}, \mathbf{J}), \mathrm{CD} 45^{+} \mathrm{F} 4 / 80^{\text {low }}+$ monocytes decreased by 6.28 fold $(\mathbf{G}, \mathbf{H}, \mathbf{I}, \mathbf{K})$ and $C D 45^{+} \mathrm{F} 4 / 80^{\text {high }}+$ macrophages decreased significantly by 5.32 fold $(\mathbf{G}, \mathbf{H}, \mathbf{I}, \mathbf{K}) .{ }^{*} \mathrm{p}<0.05$, compared to control; $\# p<0.05$, compared to Ova). Less than 0.05 of $P$ value was considered statistically significant.

protein NF- $\kappa \mathrm{B}$ expressed in OVA-treated mice and STAT6 phosphorylation, which are associated with IL-13 to develop airway remodeling. TGF- $\beta$ is involved in native T-cell differentiation into Th17 cells, which induces neutrophil airway inflammation. Our study demonstrates the inhibitory effect of Fisetin on mice model of allergic asthma. Western blot showed a reduced expression of TGF- $\beta$ in post-OVA mice lung homogenate. Published data highlighted the essential role of TGF- $\beta$ in airway fibrosis, which promotes several signaling cascades including JNK, and p38 pathway $^{28,29}$.

Different progenitor cells of the allergen-exposed mice show consistently reduced number in post-ova group, which supports the previous data of chronic allergic model of mice. Based on this study, we present a possible therapeutic mechanism of orally administered fisetin (Figure 11).

\section{CONCLUSIONS}

While our studies have shown that fisetin is effective as an anti-inflammatory agent, which can be used as a therapeutic agent in asthma, its pharmacological properties are yet to be determined. With the rising occurrence of asthma all over the world, high cost and adverse effects of current drugs, the findings of this paper can be a step towards an economical and safer therapy for asthma.

\section{COMPETING INTERESTS}

There is no conflict of interest among the authors.

\section{CONTRIBUTION OF AUTHORS}

PP performed the experiment and the assays, and analyzed the data. SM2 performed few assays. SM1 analyzed the data and wrote the manuscript. ERB initiated the project, designed the experiments, analyzed the data and wrote the manuscript. All authors approved the manuscript.

\section{ACKNOWLEDGMENTS}

We would like to acknowledge the Indian Council of Medical Research (ICMR), UGC-UPE-II and UGC- 

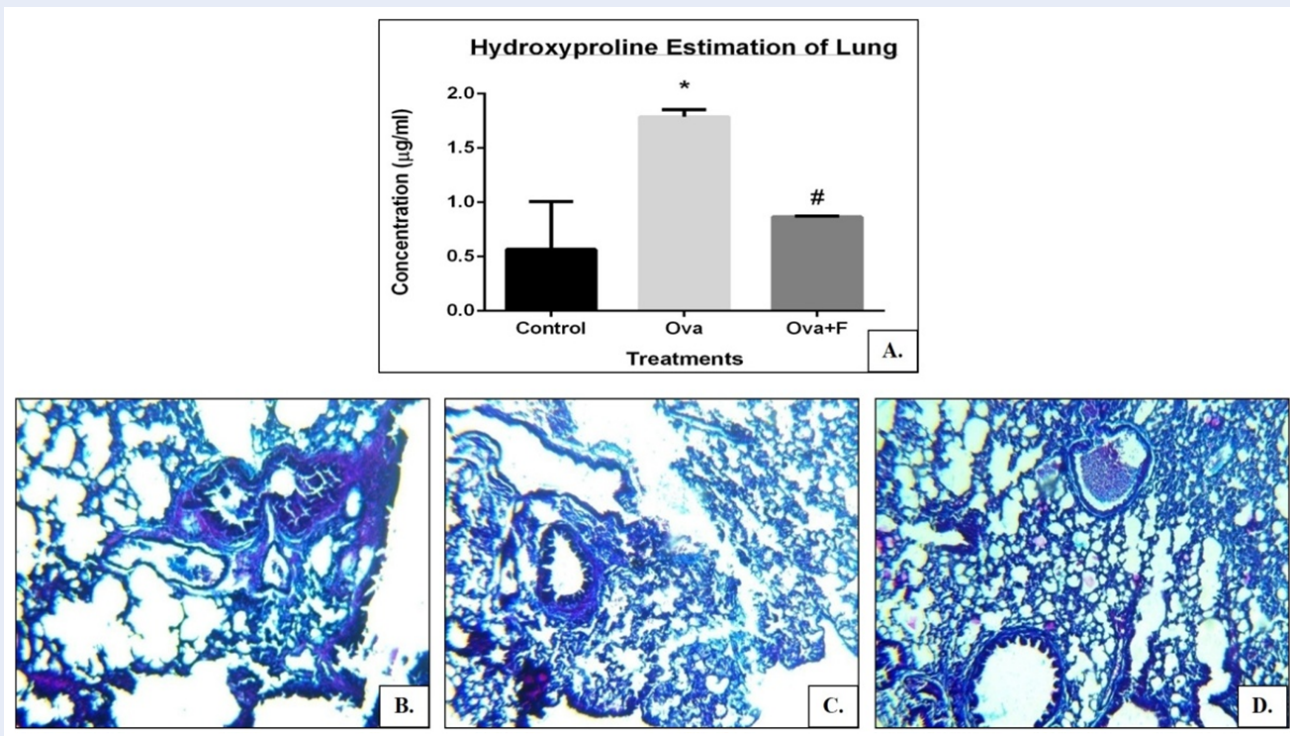

Figure 8: Fisetin inhibited collagen deposition in the lung. Collagen content in the lung 3.16 fold more with Ova, and reduced by 2.05 fold with fisetin (A). Higher quantity deposition of collagen in the lung with Ova was identified by Masson's- Trichrome stain (C), compared to control (B). Fisetin decreased the deposition of collagen (D). ( ${ }^{*} p<0.05$, compared to control; \# $p<0.05$, compared to ova). Less than 0.05 of P value was considered statistically significant.
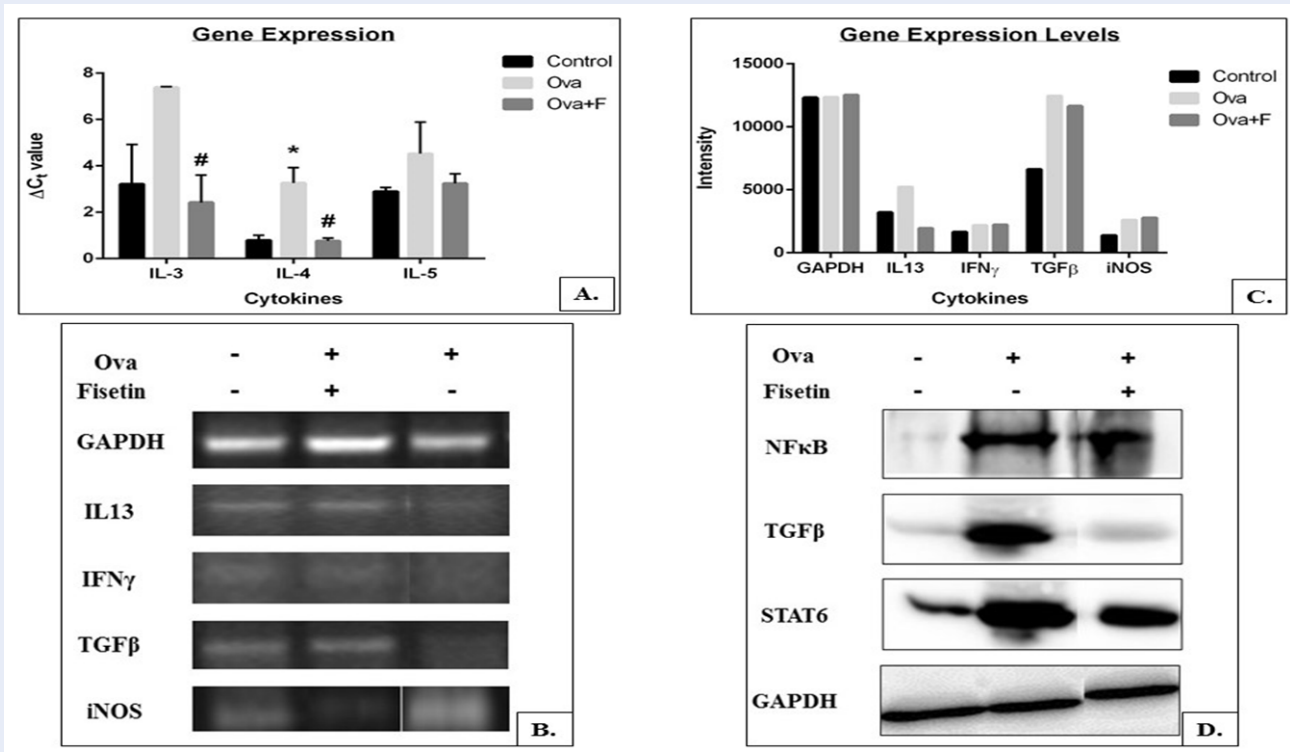

Figure 9: Fisetin inhibited the expression of pro-inflammatory cytokines and signaling molecules. Fisetin reduced the expression of IL3 by 3.05 fold, IL 4 by 4.27 fold and IL 5 by 1.40 fold respectively (A). Fisetin decreased the expression levels of IL 5 by 1.28 fold, IL13 by 2.68 fold and TGF $\beta$, by 1.07 fold respectively (B, C). Fisetin also decreased the expression of NF $\kappa B, T G F \beta$ and STAT6 (D). $\left({ }^{*} \mathrm{p}<0.05\right.$, compared to control; \# $\mathrm{p}<0.05$, compared to Ova). Less than 0.05 of $P$ value was considered statistically significant. 

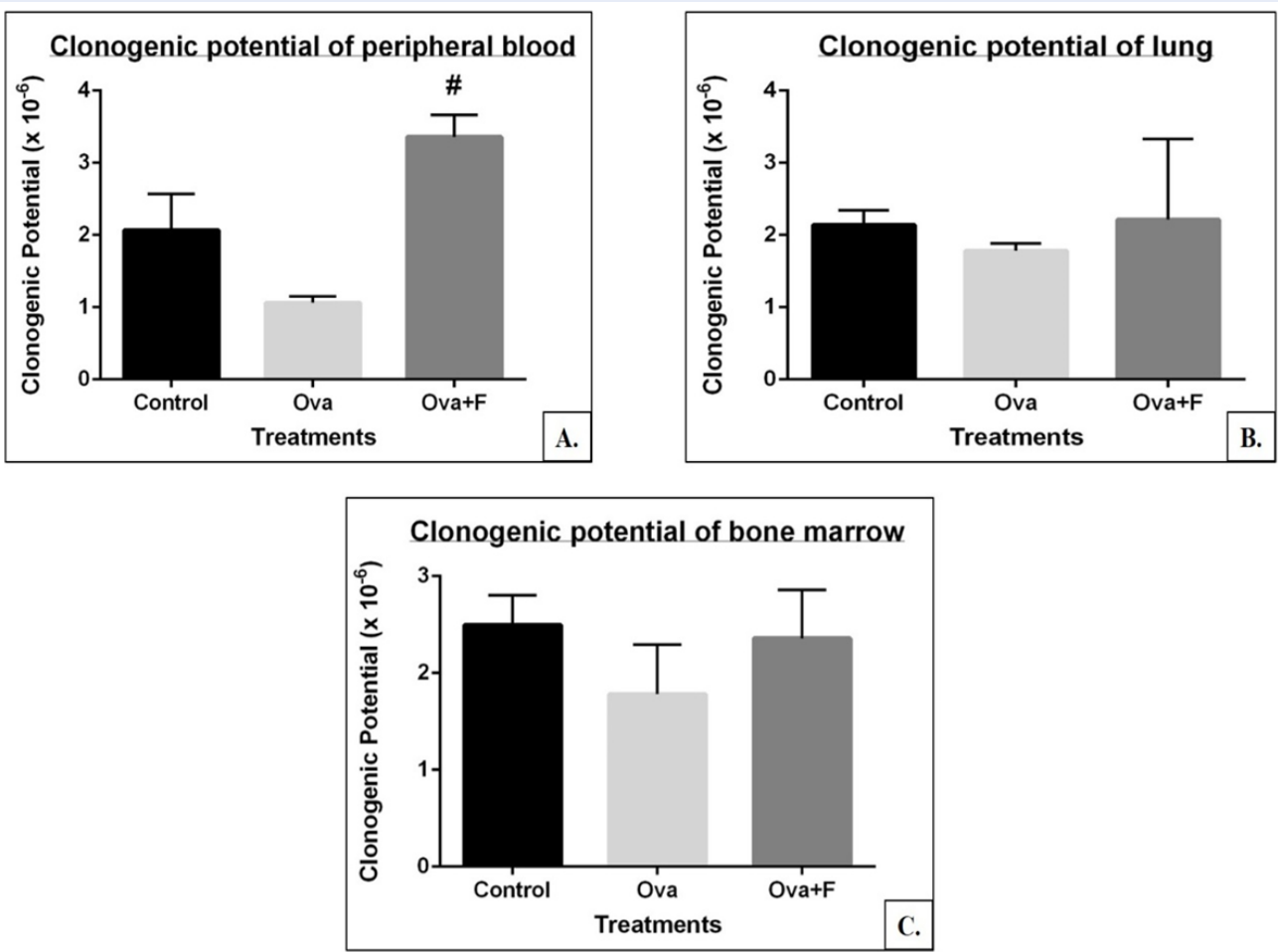

Figure 10: Clonogenic potential of cells in blood, lung and bone marrow were restored by fisetin. Clonogenic potential of blood cells reduced by 1.95 fold with Ova, and 3.17 fold increased with fisetin (A). Clonogenic potential in the lung reduced by 1.20 fold with Ova, and 1.24 fold increased with fisetin (B). Clonogenic potential in the bone marrow decreased by 1.40 fold with Ova, and 1.32 fold increased with fisetin (C). ( ${ }^{*} p<0.05$, compared to control; \# $\mathrm{p}<0.05$, compared to Ova). Denotes $\mathrm{p}$ value $<0.05$ is considered statistically significant.

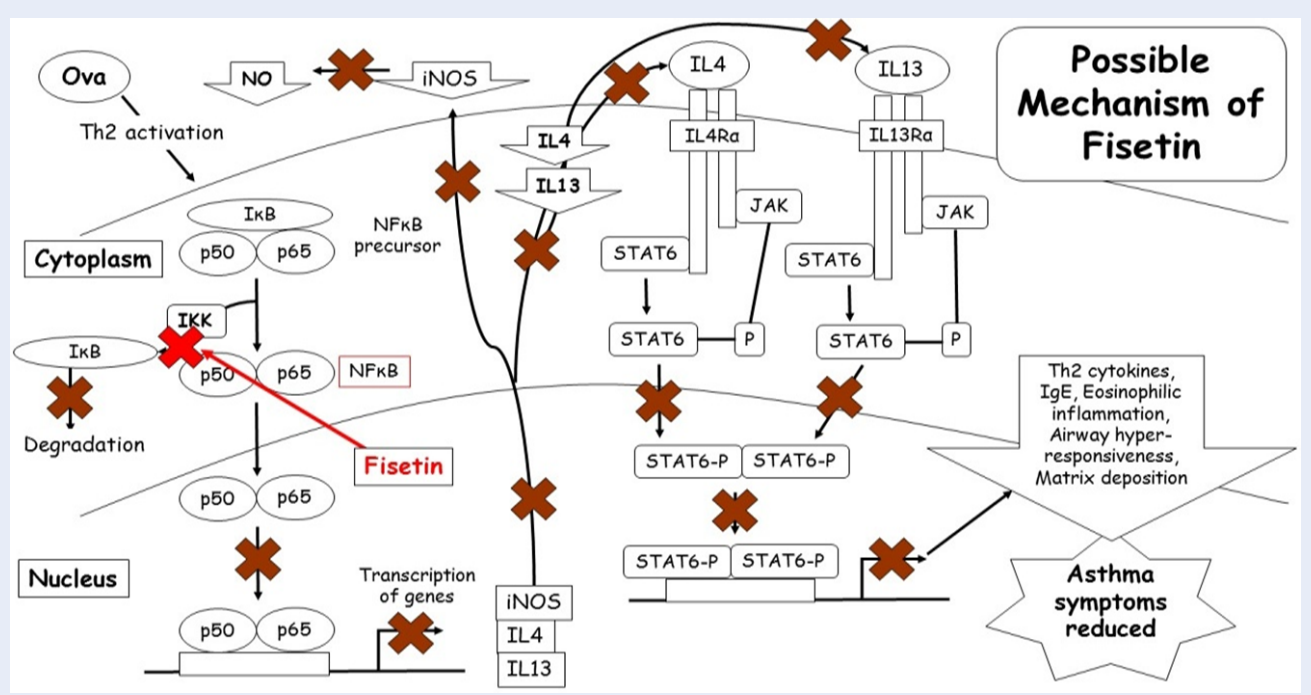

Figure 11: Inhibition mechanism of fisetin in ovalbumin sensitized bronchiole inflammation. Fisetin inactivate IKK and further protect IkB dissociation, leading to inhibit NFkB, alleviation of asthma symptoms. (The redcross indicates point of action of fisetin; brown crosses indicate down-stream consequences of inactivation of $\mathrm{NF} \kappa \mathrm{B})$. 
SAP for providing the grant, contingency and fellowship for this work.

We acknowledge the University Grants Commission (UGC), New Delhi, for providing fellowship to SM. We also acknowledge the $\mathrm{BD}-\mathrm{CoE}$ at the Centre for Research in Nanoscience \& Nanotechnology (CRNN), University of Calcutta, Kolkata, for allowing us to use the BD FACSVerse.

\section{REFERENCES}

1. Asthma; 2019. Available from: http://www.aaaai.org/ conditions-and-treatments/asthma.

2. Asthma fact sheet No.307; 2017. Available from: http://www. who.int/mediacentre/factsheets/fs307/en.

3. Manniche L. Sacred luxuries: fragrance, aromatherapy, and cosmetics in ancient Egypt. Cornell University Press; 1999.

4. Mitra S, Paul P, Mukherjee K, Biswas S, Jain M, Sinha A, et al. Mesoporous Nano-carbon particle Loaded Fisetin has a Positive Therapeutic Effect in a Murine Preclinical Model of Ovalbumin Induced Acute Allergic Asthma. J Nanomedine Biotherapeutic Discov. 2015;5:132.

5. Barnes PJ. Cellular and molecular mechanisms of asthma and COPD. Clin Sci (Lond). 2017;131(13):1541-58. PMID: 28659395. Available from: 10.1042/CS20160487.

6. Tanaka T, Takahashi R. Flavonoids and asthma. Nutrients. 2013;5(6):2128-43. PMID: 23752494. Available from: 10.3390/ nu5062128.

7. Ray A, Raundhal M, Oriss TB, Ray P, Wenzel SE. Current concepts of severe asthma. J Clin Invest. 2016;126(7):2394-403. PMID: 27367183. Available from: 10.1172/JCI84144.

8. Henderson WR, Chi EY, Maliszewski CR. Soluble IL-4 receptor inhibits airway inflammation following allergen challenge in a mouse model of asthma. J Immunol. 2000;164(2):108695. PMID: 10623860. Available from: 10.4049/jimmunol.164.2. 1086.

9. Cho JY, Miller M, Baek KJ, Han JW, Nayar J, Lee SY, et al. Inhibition of airway remodeling in IL-5-deficient mice. J Clin Invest. 2004;113(4):551-60. PMID: 14966564. Available from: 10.1172/JCI19133.

10. Panche AN, Diwan AD, Chandra SR. Flavonoids: an overview. J Nutr Sci. 2016;5:e47. PMID: 28620474. Available from: 10. 1017/jns.2016.41.

11. Maher P, Akaishi T, Abe K. Flavonoid fisetin promotes ERK-dependent long-term potentiation and enhances memory. Proc Natl Acad Sci USA. 2006;103(44):16568-73. PMID: 17050681. Available from: 10.1073/pnas.0607822103.

12. Pal HC, Pearlman RL, Afaq F. Fisetin and Its Role in Chronic Diseases. Adv Exp Med Biol. 2016;928:213-44. PMID: 27671819. Available from: 10.1007/978-3-319-41334-1_10.

13. Wu MY, Hung SK, Fu SL. Immunosuppressive effects of fisetin in ovalbumin-induced asthma through inhibition of NF- $\$ \kappa$ B activity. Journal of agricultural and food chemistry. 2011;59(19):10496-10504.

14. Khan N, Syed DN, Ahmad N, Mukhtar H. Fisetin: a dietary antioxidant for health promotion. Antioxidants \&amp; redox signaling. 2013;19(2):151-162.

15. Shakeri F, Boskabady MH. Anti-inflammatory, antioxidant, and immunomodulatory effects of curcumin in ovalbumin- sensitized rat. Biofactors. 2017;43(4):567-76. PMID: 28509396. Available from: 10.1002/biof.1364.

16. Banerjee ER, Jiang $\mathrm{Y}$, Henderson WR, Latchman $\mathrm{Y}, \mathrm{Pa}$ payannopoulou T. Absence of alpha 4 but not beta 2 integrins restrains development of chronic allergic asthma using mouse genetic models. Exp Hematol. 2009;37(6). PMID: 19463772. Available from: 10.1016/j.exphem.2009.03.010.

17. Chauhan PS, Dash D, Paul BN, Singh $R$, et al. Intranasal curcumin ameliorates airway inflammation and obstruction by regulating MAPKinase activation (p38, Erk and JNK) and prostaglandin D2 release in murine model of asthma. International immunopharmacology. 2016;31:200-206.

18. Han H, Ziegler SF. Bronchoalveolar Lavage and Lung Tissue Digestion. Bio Protoc. 2013;3(16):e859. PMID: 27390755. Available from: 10.21769/BioProtoc.859.

19. Sood R. Medical Laboratory Technology: Methods and Interpretations. vol. Volume I. India: Jaypee Brothers Medical Publishers Pvt Ltd; 2009.

20. Paul P, Majhi S, Mitra S, Banerjee ER. Immuno-modulatory and Therapeutic Effect of Curcumin in an Allergen-sensitized Murine Model of Chronic Asthma. J Clin Cell Immunol. 2018;9(03):551. Available from: 10.4172/2155-9899.1000551.

21. Dahl R. Systemic side effects of inhaled corticosteroids in patients with asthma. Respir Med. 2006;100(8):1307-17. PMID: 16412623. Available from: 10.1016/j.rmed.2005.11.020.

22. Syed DN, Adhami VM, Khan N, Khan Ml, Mukhtar H. Exploring the molecular targets of dietary flavonoid fisetin in cancer. In: Seminars in cancer biology. vol. 40; 2016. p. 130-140.

23. Nagai K, Takahashi Y, Mikami I, Fukusima T, Oike H, Kobori M. The hydroxyflavone, fisetin, suppresses mast cell activation induced by interaction with activated T cell membranes. $\mathrm{Br} J$ Pharmacol. 2009;158(3):907-19. PMID: 19702784. Available from: 10.1111/j.1476-5381.2009.00365.x.

24. Huang W, Li ML, Xia MY, Shao JY. Fisetin-treatment alleviates airway inflammation through inhbition of MyD88/NF- $\kappa B$ signaling pathway. Int J Mol Med. 2018;42(1):208-18. PMID: 29568921. Available from: 10.3892/ijmm.2018.3582.

25. Brewer JP, Kisselgof AB, Martin TR. Genetic variability in pulmonary physiological, cellular, and antibody responses to antigen in mice. Am J Respir Crit Care Med. 1999;160(4):11506. PMID: 10508801. Available from: 10.1164/ajrccm.160.4. 9806034.

26. Whitehead GS, Walker JK, Berman KG, Foster WM, Schwartz DA. Allergen-induced airway disease is mouse strain dependent. Am J Physiol Lung Cell Mol Physiol. 2003;285(1):32-42. PMID: 12626335. Available from: 10.1152/ajplung.00390.2002.

27. Yamaguchi Y, Suda T, Suda J, Eguchi M, Miura Y, Harada N, et al. Purified interleukin 5 supports the terminal differentiation and proliferation of murine eosinophilic precursors. J Exp Med. 1988;167(1):43-56.

28. Massagué J, Blain SW, Lo RS. TGFbeta signaling in growth control, cancer, and heritable disorders. Cell. 2000;103(2):295309. PMID: 11057902. Available from: 10.1016/S0092-8674(00) 00121-5.

29. Imamichi Y, Waidmann O, Hein R, Eleftheriou P, Giehl K, Menke A. TGF beta-induced focal complex formation in epithelial cells is mediated by activated ERK and JNK MAP kinases and is independent of Smad4. Biol Chem. 2005;386(3):225-36. PMID: 15843168. Available from: 10.1515/BC.2005.028. 